\title{
Comparison of Seismic isolation with U-shaped metallic isolator and Soil structure Interaction
}

\author{
G. Jyothi Sravya ${ }^{1}$ and $A$. Manchalwar ${ }^{2}$
}

${ }^{1}$ M-Tech Scholar, Gokaraju Rangaraju Institute of Engineering and Technology, Hyderabad.

${ }^{2}$ Associate Professor, Gokaraju Rangaraju Institute of Engineering and Technology, Hyderabad

\begin{abstract}
Soil condition is an important research area in earthquake engineering. In this work we evaluated the impact of soil-structure interaction (SSI) and U-shaped steel damper on the isolated response of the building base. Different soils for a seismic performance of multistory buildings are systematically compared and discussed. The soil's physical state is divided into; hard soil, medium soil, and soft soil. It was compared with the U-shaped steel damper and there is noticeable difference between them. This study concludes that the use of steel damper shaped and SSI has been effective in minimizing structural response. It was observed that interaction of the soil structure provides some flexibility to the structure by increasing the structure's displacements. Modeling base isolation along with consideration of soil structure interaction therefore leads to better structural response prediction.
\end{abstract}

\section{Introduction}

The soil condition is an important research field; the soil's physical state and dynamic properties, which can be divided into hard soil, medium soil, soft soil, as per standard Indian code. The seismic demands on the superstructure are decreased by the natural action of time elongation, increased damping, and energy dissipation. Although the buildings are in the same area, the same structure, the same magnitude of the earthquake, earthquake damage is not same type. That means there are also other factors which affect the damages conditions, like internal soil quality, ground movement characteristics, mass, stiffness and vertical deviations. The effect with SSI on the structural response has been explained by the analysis of results which were obtained for two models: model 1 was mentioned by an isolated structure with SSI and the second model was represented by an isolated base structure without SSI. Three types of soil, namely hard, medium, and soft soils, have been considered in the investigations described, as mentioned in FEMA 356. U-shaped steel damper and another structure with SSI supported the base isolated structure. The dampers greatly reduced factors of damage such as drift and also displacement. Reduces systemic responses to external forces that can be done by the use of special protective systems. Seismic insulation technology for newly built buildings may be used to avoid these losses.[1] In comparison with Lead rubber bearings, Atulkumar and Bakre investigated the U-shaped metallic isolator output for seismic safety in RC buildings [2]. Bahekar and. Al., discovered the effects of SSI on response of isolated base buildings. By introducing stability at the base and minimizing resonance with predominant frequency of earthquakes, seismic isolation will greatly reduce the earthquake motions caused on the relative stiffness of building[4]. Amer Hassan and Shilpa Pal had conducted nonlinear time history, and an analysis of the response spectrum was conducted using Etabs2015 software to study soil effects under the isolated base [5]. Tsai and Hsueh investigated the locations, higher models and damping of soil structure interaction (SSI) in base isolated system which is based in multiple layers of half-space sand [6]. It is the same in Spyrakos' research where he investigated The effects of soil structure interaction (SSI) on the response of multi-storey base-isolated buildings constructed through an elastic soil layer overhanging a rigid foundation rock and subject to harmonic ground movements [7]. 


\section{Soil Structure Interaction and U- shape isolator}

Geological problems cause earthquake damage, and hundreds and thousands of lives have been harmed as a result of the earthquake in recent years, and technological improvements have significantly reduced death numbers. The aim of simple isolation is to uncouple the upper structure from the further injuries which are caused by an earthquake are needed to get minimized and also the civil engineers will create solutions. The use of SSI was explained to the base in seismic study, thus reducing the internal structural forces. Economic damage, loss of life and improved seismic performance of civilian structures. In the 1980s and 1990s SSI was studied using numerical methods.

The U-shaped metallic isolator is a modern high quality metallic damper made from the steel. It absorbs seismic energy and makes use of repair strength balanced features to minimize motion during earthquakes. The base insulation U-shaped metallic isolator exhibits approximately the same hysteretic behavior in all directions (360o). It is economical in comparison with standard base insulation steel rod dampers, with low cost compared to the shear yield strength point. The extent of damage caused by an earthquake may be assessed visually. The damper portion may also be substituted in the unlikely event this is required after the seismic activity.
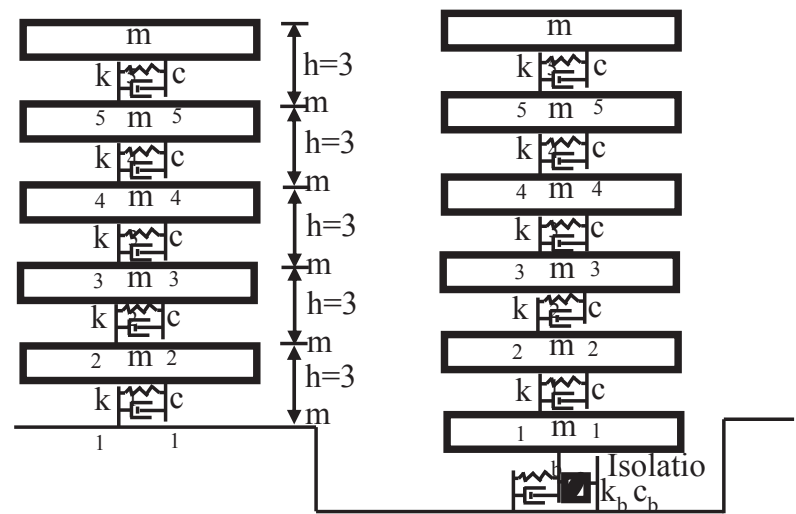

Fig 1. Schematic 5-story fixed-base as well as base-isolated structure model (e.g. A. Matsagar and R.S. Jangid )

The above representation relates to the base isolation of the structure with U-shaped damper and another with contact of the soil structure. First the total mass is measured and then the soil stiffness was added individually to the structure for all 3 different type of soils in the $\mathrm{X}, \mathrm{Y}$ and $\mathrm{Z}$ axis respectively.

A basic SDOF is based on an isolated 5-story base house, it is taken from Zhang and Philips (2015) as direct representation of a basic low-rise structure. The basic fixed base structure of the superstructure is 0.54 $\mathrm{s}$, and the ratio of damping is $2 \%$. For reference, see. Zhang, and so forth. (2009). (2015). Table-1 displays the parameters of a model. The model shown in the fig is dependent isolation with the conditions of SSI and base isolation without SSI, and the model had a lumped parameter with one degree of freedom on each plot. It's expected that all external excitations would keep this model linear-elastic.

Table 1. The parameters of a 5-Story Isolated-Base with SSI and without SSI models.

\begin{tabular}{ccl}
\hline $\begin{array}{c}\text { Floor mass } \\
\text { in } \\
(\mathrm{kg})\end{array}$ & $\begin{array}{l}\text { Story Stiffness } \\
\text { in } \\
(\mathrm{kN} / \mathrm{m})\end{array}$ & $\begin{array}{l}\text { Damping } \\
\text { coefficient } \\
\text { in }(\mathrm{kg} / \mathrm{s})\end{array}$ \\
\hline $\mathrm{c}_{1}=$ & $\mathrm{m}_{1}=53,073$ & $\mathrm{k}_{1}=101,196$ \\
34,814 & & \\
$\mathrm{c}_{2}=30,138$ & $\mathrm{~m}_{2}=53,073$ & $\mathrm{k}_{2}=87,279$ \\
$\mathrm{c}_{3}=29,618$ & $\mathrm{~m}_{3}=53,073$ & $\mathrm{k}_{3}=85,863$ \\
$\mathrm{c}_{4}=25,981$ & $\mathrm{~m}_{4}=53,073$ & $\mathrm{k}_{4}=74,862$ \\
$\mathrm{c}_{5}=19,745$ & $\mathrm{~m}_{5}=53,073$ & $\mathrm{k}_{5}=57,177$ \\
\hline
\end{tabular}

Table 2. Properties of different types of soil

\begin{tabular}{|l|l|c|c|c|c|}
\hline $\begin{array}{c}\text { Typ } \\
\text { es }\end{array}$ & $\begin{array}{c}\text { Soil } \\
\text { Type }\end{array}$ & $\begin{array}{c}\text { Shear } \\
\text { Veloci } \\
\text { ty } \\
(\mathrm{m} / \mathrm{sec} \\
2)\end{array}$ & $\begin{array}{l}\text { Poiso } \\
\text { ns } \\
\text { Ratio }\end{array}$ & $\begin{array}{c}\text { Unit } \\
\text { weigh } \\
\mathrm{t} \\
(\mathrm{kN} / \\
\left.\mathrm{m}^{3}\right)\end{array}$ & $\mathrm{E}_{\mathrm{s}}$ \\
\hline $\begin{array}{l}\text { Typ } \\
\text { e-I }\end{array}$ & $\begin{array}{l}\text { Hard } \\
\text { Soil }\end{array}$ & 1200 & 0.3 & 22 & $\begin{array}{c}8.40 \mathrm{E} \\
+6\end{array}$ \\
\hline $\begin{array}{l}\text { Typ } \\
\text { e-II }\end{array}$ & $\begin{array}{l}\text { Mediu } \\
\text { m Soil }\end{array}$ & 600 & 0.35 & 18 & $\begin{array}{c}4.46 \mathrm{E} \\
+5\end{array}$ \\
\hline $\begin{array}{l}\text { Typ } \\
\text { e-III }\end{array}$ & $\begin{array}{l}\text { Soft } \\
\text { Soil }\end{array}$ & 150 & 0.4 & 16 & $\begin{array}{c}1.03 \mathrm{E} \\
+5\end{array}$ \\
\hline
\end{tabular}

Table 3. Soil bearing capacity

\begin{tabular}{|l|c|c|}
\hline Soil Type & $\mathrm{kg} / \mathrm{m}^{2}$ & $\mathrm{kN} / \mathrm{m}^{3}$ \\
\hline Hard Soil & 330000 & 3300 \\
\hline Medium Soil & 165000 & 1650 \\
\hline Soft Soil & 45000 & 450 \\
\hline
\end{tabular}

\section{Dynamic Response:}

The acceleration of the structure clearly demonstrates how much force earthquake motion exerts on the structure. Graph shows the acceleration of the superstructure for four different earthquakes and provides a comparison between Interaction with the soil structure and isolated buildings. Both the 
isolation device provides a unique reduction in the acceleration of the superstructure.
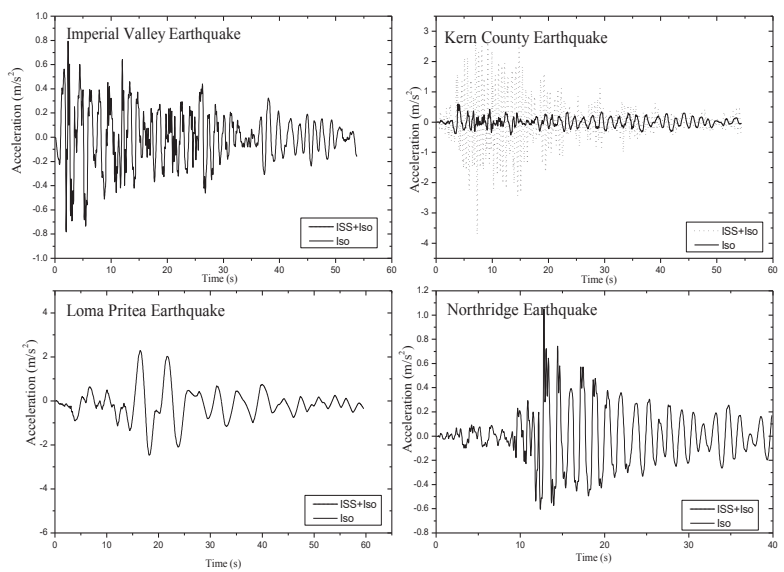

Fig 2. Comparison of Hard Soil Interaction and U-shaped Damper
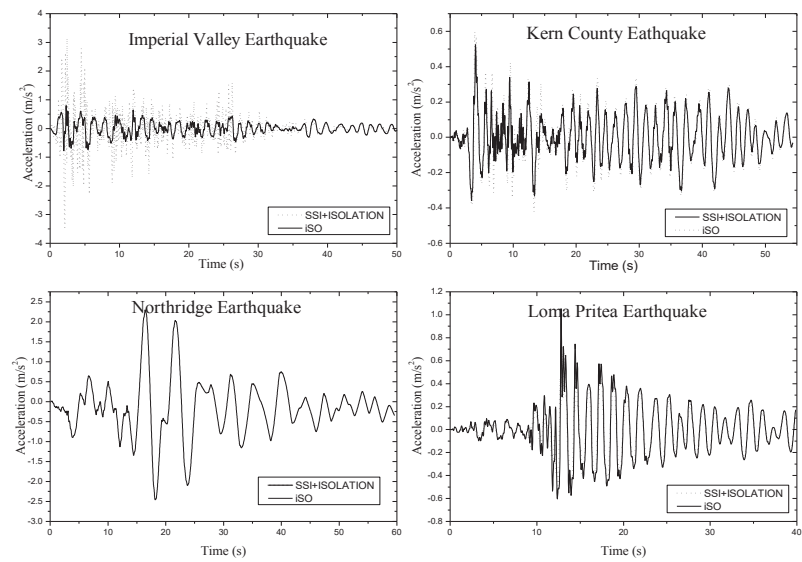

Fig 3. Comparison of Medium Soil Interaction and Ushaped Damper
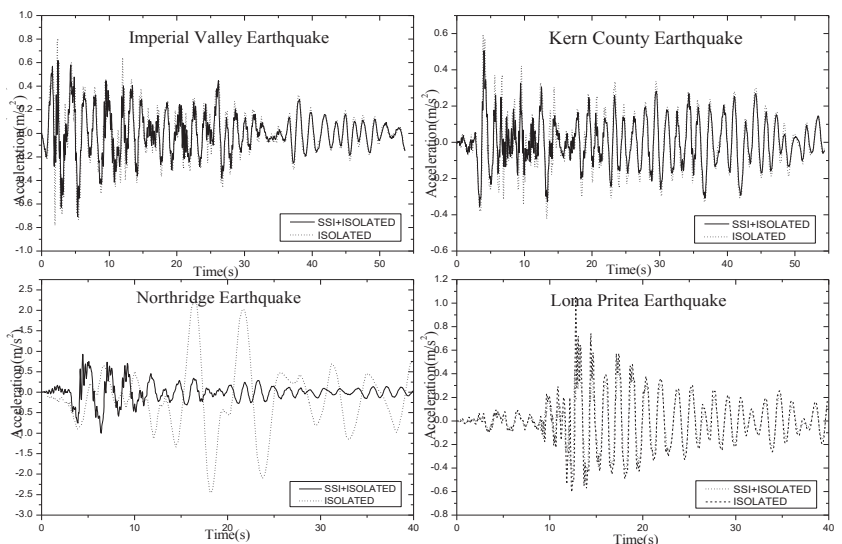

Fig-4 Comparison of Soft Soil Interaction and U-shaped Damper

\section{Conclusions}

The structure was analyzed using 5 floors with an isolated base with SSI and the isolated base without
SSI which was analyzed using Time History Analysis in SAP2000 software for 3 different soil conditions. The aim of the analysis is to examine the seismic performance under 4 real ground motions of an isolated base building; the structural responses are as follows:

1. Displacements, accelerations were studied.

2. The assumptions can be stated after the model analysis as it has been noted That the share shear value increases with lower soil stiffness, and is found to be the highest for soft soil (SS) and the lowest for hard soil (HS).

3. Generally it is concluded that structural isolation with soil affects the response of the seismic loaded building.

4. Interaction of soil structure decreases its efficiency of the structure by making the structure more flexible and thus the structure is more deformed.

\section{References}

1. G. Jyothi Sri Sravya, Atulkumar Manchalwar, Seismic Isolation System using U-Shaped Steel Damper, International Journal of Recent Technology and Engineering (IJRTE) ISSN: 2277-3878, Vol.8 Issue-4, November-2019, pp. 12336-12339.

2. A. Manchalwar and S.V. Bakre, Seismic performance of structure with isolated foundation using U-shaped steel damper as an isolator, Soil mechanics and foundation Engineering, Vol.15 No.2.

3. R.S. Jangid and V.A. Matsagar, Influence of isolator characteristics on the response of baseisolated structures, May. 2018, pp.1735-1749.

4. Rohini L. Bahekar, Kuldeep Dabhekar, Atulkumar Manchalwar, Seismic Response of Structure Equipped with Lead Rubber Bearing Considering SSI, IOSR Journal of Engineering, pp. 48-52.

5. Shilpa Pal and Amer Hassan, Effect of soil condition on seismic response of isolated base buildings, International Journal of Advanced Structural Engineering, Vol.10 September-2018 pp. 249-261.

6. C. S. Tsai, C. I. Hsueh and H. C. Su, Roles of soil-structure interaction and damping in baseisolated structures built on numerous soil layers overlying a half-space, Earthquake engineering and engineering vibration, Vol.15, No.2, June2016, pp. 387-400.

7. C.C. Spyrakos, Ch. A. Maniatakis and I.A. Koutromanos, Soil-structure interaction effects on base-isolated buildings founded on soil 
stratum, Engineering Structures, Vol.31, October-2008, pp.729-737.

8. Sayed Mahmoud, Per-Erik Austrell and Robert Jankowski, Non-linear behaviour of baseisolated building supported on flexible soil under damaging earthquakes, Key Engineering Materials, September-2011, pp. 142-145.

9. J. Enrique Luco, Effects of soil-structure interaction on seismic base isolation, Soil Dynamics and Earthquake Engineering, Vol. 66, May 2014, pp.167-177.

10. Erfan Alavi, Soil-Structure Interaction Effects on Seismic Behaviour of Base-Isolated Buildings, International Institute of Earthquake Engineering and Seismology, IIEES.

11. Yogeswara Reddy B, Srinivas Rao J, Suresh Kumar T, Nagarjuna A, International Journal of Innovative Technology and Exploring Engineering, Vol. 8 no. 11, pp: 1194-1198, (2019).

12. Turan Karabork, I. O. Deneme and Pelin Bilgehan, A comparison of the effect of SSI on base isolation systems and fixed-base structures for soft soil, Geomechanics and Engineering, August 2014.

13. Ruiyang Zhang and Brian M. Phillips, A.M.ASCE, Performance and Protection of Base-Isolated Structures under Blast Loading, Journal f Engineering Mechanics, May-2015.

14. Zhuang Haiyang, $\mathrm{Yu} \mathrm{Xu}, \mathrm{Zhu}$ Chao and Jin Dandan, Shaking table tests for the seismic response of a base-isolated structure with the SSI effect, Soil Dynamics and Earthquake Engineering, Vol. 67, September 2014, pp. 208218.

15. Davide Forcellini, Seismic assessment of a benchmark based isolated ordinary building with soil structure interaction, Bull Earthquake Eng, November-2017.

16. Takaji Kokusho, Seismic base-isolation mechanism in liquefied sand in terms of energy, Soil Dynamics and Earthquake Engineering, Vol.63, March-2014, pp. 92-97.

17. Tummala Suresh Kumar, Kosaraju Satyanarayana, Materials Today: Proceeding, 26 (2), 3228-3233, (2020). 